\title{
The laboratory of mathematics in primary school: a practical approach for understanding and learning
}

\author{
Paolo Di Sia \\ Free University of Bolzano-Bozen, Viale Ratisbona 16, 39042 Bressanone-Brixen, Italy \\ E-mail address: paolo.disia@gmail.com
}

\begin{abstract}
The skills of mathematical nature are currently necessary and fundamental to properly understand and adequately use the increasing amount of scientific and technological knowledge of everyday life. In this work we introduce interesting results of current research about the importance of the connection between the natural intuitive mathematics and the "scholastic mathematics", putting it on a motivating and meaningful basis for the students already by the first year of primary school. To do this, a didactics of laboratory is useful, i.e. a practical approach for better understanding and using the formal approach. Through the mathematics laboratory it is possible to create activities, which support the transition from intuitive notions and early elementary operational levels to more advanced forms of thought. The laboratory of mathematics is understood both as physical place and as a moment in which the child is active, discusses and argues their own choices, does experimentation and learns how to collect data and to compare them with the models. In conclusion some examples of mathematics laboratory activities for the first primary class are also given.
\end{abstract}

Keywords: Mathematics; Laboratory; Education; Experimental Technology; Science; Primary School

\section{INTRODUCTION}

Speaking about mathematics and its world, many people think to a set of symbols and ideas related to a particular reality, disconnected from the concrete context of everyday life; this considerable prejudice is one of the causes of disinterest and separation from this discipline. Mathematics is remembered by many adults as boring, difficult, far from reality; their reasons seem to be various:

1) it is a discipline in which we study only numbers and figures, calculating measurements (lengths, areas, volumes), studying their properties;

2) to study mathematics does not mean to reflect on concrete, but only on abstract;

3) mathematics is not a creative discipline, because it is already quite defined, established in its concepts and rules; it does not appear to make space for creativity and therefore is not fun.

The above listed argumentations have been chosen among many of them and are fairly common, but these do not really take into account of the deep, articulate, complex and global value of mathematics. Mathematics develops across a range of languages and through a symbolic way of thinking, encoded within models of abstract nature, but it is one of the most 
training disciplines in the development of human thought in its various aspects. The study and work with mathematics are therefore one of the main tasks of any adequate educational project [1-3].

\section{THE WORLD OF MATHEMATICS}

The teaching of mathematics offers an intellectual tool of great importance, in particular in relation to the following points:

1) The skills of mathematical nature have become necessary and basic in the current reality, for understanding, interpreting and appropriately using the large and growing quantity of scientific and technological knowledges, useful and often indispensable in daily life.

2) Mathematics education helps in the formation of a rational and critical structure of thought, which makes it an effective and necessary tool of cultural and human growth.

3 ) It is important to connect the intuitive natural mathematics with the scholastic, formal one, gradually taking familiar and inserting the second on a motivating and meaningful basis for students. For doing that, a laboratory teaching is important, a practical approach to understand and better use the formal approach.

Through the laboratory, it is possible to build activities which promote the transition from intuitive notions and early elementary operational levels to more advanced forms of thought. These progresses will be involved in secondary school in mathematical proofs, in advanced algebraic calculus, in the use of mathematical models in different contexts. The laboratory allows also a bodily and experiential approach to measures, in connection with natural sciences, for deriving relationships among the encountered variables and for getting models of the studied phenomena. In this way we provide students with important opportunities for building new concepts and skills, for enriching the meaning of learned concepts, for verifying the operativity of the previously achieved learning outcomes.

Starting from primary school, it should try to build a knowledge on subject, on class and on own acts, through the analysis of their practices, the critical review and the constructive dialogue.

This approach seeks to avoid the process in which the theory seems to be proposed from outside and/or imposed from above, and the creation of a separation of teachers from their practice, which on fact does not help in the construction of an effective knowledge.

Therefore the important purpose is to reflect on practice and to get from it useful models for future actions. The reflective activity has also two important functions:

a) for continuous training of teachers;

b) as opportunity for research, in which researchers accompany and guide the practice, through a collaborative approach between research and education.

For indicating the important adapting task to the characteristics of the educational dialogue, taking place in the classroom between teacher and students, we talk about "didactic transposition". One of tasks that each teacher has to deal daily is identified with the correct didactic transposition of knowledge related to the taught discipline. In this way the teachers fulfill to the "management of their continuous training" [4]. 
The teacher becomes aware of her/his educational philosophy, following a "practicetheory-practice" path, trying to produce an effective and creative knowledge, which can solve practical problems.

\section{THE LEARNING}

The learning is the ultimate goal of teaching, the destination where efforts, thoughts, research are centered. It is a complex phenomenon involving characteristic aspects of different sciences, ranging from education to psychology, from history to philosophy.

Interesting studies show that students usually solve school problems without posing the problem of the contact with reality; they perceive a situation, which is not directly personally experienced; it is thus necessary to propose the situation in a real motivating way. Consequently, they will build a mental image, a mathematical model of the described situation, for arriving to a concrete solution.

The potential of the student should be promoted and developed, for acquiring an autonomous capacity in dealing with the changes in the social and cultural conditions.

From primary school, it is certainly possible to draw inspiration from everyday experiences of children and the encountered obstacles. From these experiences, links involving students in a comprehensive manner can be created; doing that, the major obstacles, which may result from the bad understanding of the text of the problem, from the use of particular not immediately known terms, so as from the data elaboration, are detected.

Teachers need to implement strategies in relation to the analysis of texts, vocabulary and key words, trying to move from concrete to abstract.

The educational research has identified five main obstacles, related to:

1) the difficulty of transfer;

2) the functional fixity;

3) the effect of custom;

4) setting not needed limits;

5) the inability to use the information provided by the problem $[2,5,6]$.

There are also common encountered errors by students, classified in a "hierarchy of errors"; the main mistakes occur during the reading of the text of problem, so as by the understanding and transformation into a mathematical model.

The "ministry guidelines on the role of mathematics in primary school" indicate the specific role of mathematics in development of:

a) the general ability to work and communicate meanings with formalized languages;

b) the use of such languages to represent and build models of relationships among objects and events;

c) to provide tools for the scientific description of the world and to deal with problems of everyday life;

d) the ability to communicate and discuss, to correctly argue, to understand views and arguments of the others;

e) the ability to perceive and explore fascinating relationships and structures, which we find in nature and in the creations of man. 
Mathematics is included within the "mathematical-scientific-technological" area, which has the global aim of "providing tools to perceive, interpret and link natural phenomena, concepts and man-made artifacts, everyday events". In addition, it aims to develop the ability to critique and judgment, the awareness of motivating personal statements, the aptitude to understand arguments and points of view, that are different from their own [1-3,7].

\section{THE DIDACTICS OF LABORATORY}

The didactics of laboratory is intended both as a physical place, and as a moment in which the student is active, discusses and argues her/his own choices, builds meanings, learns to collect data and to compare them with the models. In this general sense, the laboratory is not only specific for experimental sciences, but it is an important modality also in the learning of mathematics [8].

Mathematics is not a static out of time reality, but it has an history and is constantly changing, like the other sciences. It is important for valorizing the experience and knowledges of the students, the discovery, the collaborative learning. This learning must also be done through practice, discussion, exploration, development of thinking about the practice and way for building knowledge.

Equally important is the role of development of procedural skills (mental, written, graphic, through computational tools), the memorization (for example of definitions and properties of mathematical objects), and of mathematics in its globality as theoretical construction [9].

\section{EXAMPLES OF LABORATORY ACTIVITIES FOR THE BEGINNING OF PRIMARY SCHOOL}

\begin{tabular}{|c|c|c|c|c|c|c|c|c|c|}
\hline 0 & ב & 2 & 8 & 4 & $\underline{5}$ & 6 & 7 & 8 & 9 \\
\hline 10 & 1] & 12 & 13 & 14 & 15 & 16 & 17 & 16 & 19 \\
\hline 20 & 21 & 22 & 23 & 24 & 23 & 26 & 27 & 28 & 29 \\
\hline g & 81 & 32 & 88 & 34 & 55 & 186 & 87 & 188 & $\$ 8$ \\
\hline+5 & +1 & +2 & -13 & 44 & 45 & 46 & $\$ 7$ & 16 & 10 \\
\hline$\leqslant$ & $\Delta 1$ & $\$ 82$ & ss & 54 & SS & $\$ 8$ & 57 & $\leqslant 8$ & $\$ 9$ \\
\hline 60 & 61 & 62 & 63 & 64 & 65 & 66 & 67 & 66 & 69 \\
\hline סד & $\pi$ & 72 & 73 & 74 & 75 & 76 & $T_{7}$ & 78 & 70 \\
\hline 80 & 81 & 82 & 83 & 84 & 85 & 86 & 87 & 88 & 38 \\
\hline 90 & 9] & 92 & 95 & 94 & 95 & 96 & 97 & 98 & 99 \\
\hline
\end{tabular}

\begin{tabular}{|c|c|c|c|c|c|c|c|c|c|}
\hline & 1 & 2 & 3 & 4 & 5 & 6 & 7 & 8 & 9 \\
\hline 0 & 11 & 12 & & 14 & 15 & 16 & 17 & 16 & 19 \\
\hline 25 & 21 & 22 & 23 & 24 & 23 & 26 & & 28 & 29 \\
\hline 80 & s1 & 32 & 38 & & gs & 36 & 37 & 38 & 19 \\
\hline+5 & +1 & +2 & 43 & 4 & 45 & 46 & +7 & t6 & \\
\hline$\leqslant 0$ & & $\$ z$ & 58 & 54 & $5 s$ & $\leqslant 8$ & 57 & 58 & 20 \\
\hline 60 & 61 & & 63 & 64 & 65 & 66 & 67 & 66 & 69 \\
\hline 70 & $\pi$ & 72 & 73 & & 75 & 76 & $T$ & 78 & 70 \\
\hline 80 & 81 & 82 & 33 & 84 & 85 & 86 & 87 & & 89 \\
\hline 0 & 91 & 92 & 93 & 94 & & 96 & & 98 & 99 \\
\hline
\end{tabular}

(b) 

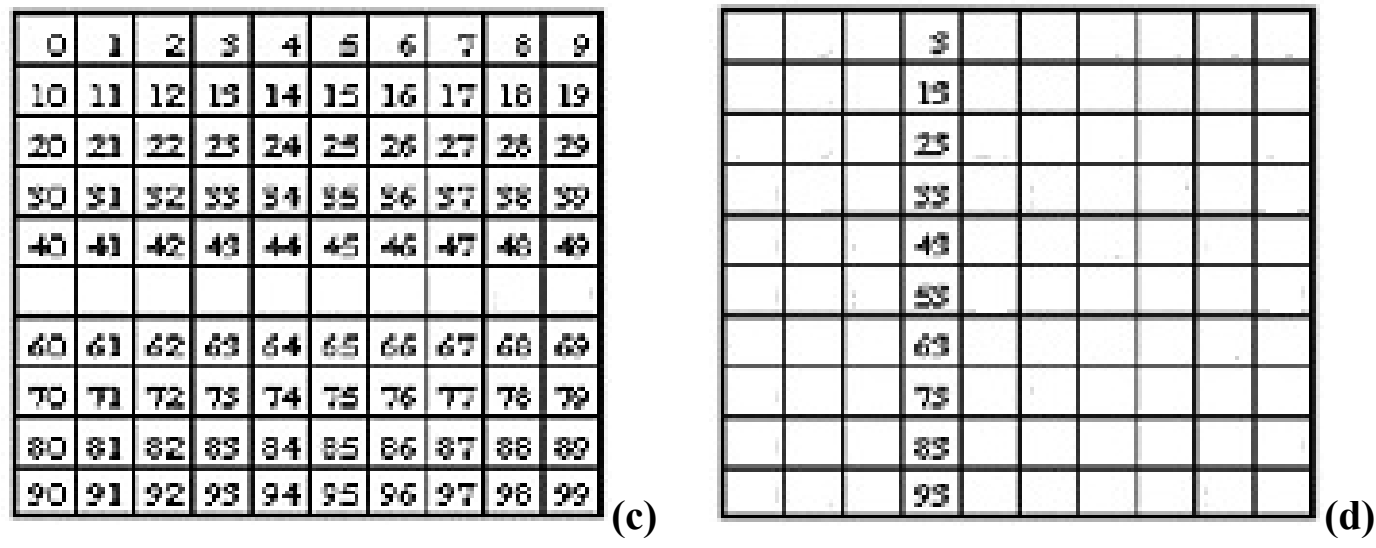

Figure 1. Numbers from 0 to 99 in the form of square.

We consider three examples of laboratory activities of mathematics in the classroom.

\section{A. Disposition of numbers}

It is possible to use the disposition of the numbers from 0 to 99 (from 1 to 100 when numbers with three digits are already introduced) in the form of square, for "games" that help children to improve the understanding of the numbering system structure, in particular with regard to the different function of tens with respect to units (Figure 1 (a)). The size of the square can be also bigger, like a poster, with the function of a castle with hundred rooms; the numbering could also be inverted, i.e. with the numbers that grow moving from bottom.

The teacher hides the number of some rooms with objects and students must find the not visible numbers. The class can be divided into small groups; a student of the group gives the answer, the other members confirm or deny, then there is the control. It is possible that some students are not able to properly express the number, using expressions like "there is a 3 in front of and behind a 1" for " 31 "; in each case this is the beginning of understanding the structure of natural numbers, the set $\mathbb{N}$.

The same "game" can be repeated in the form of written exercise with graded increasing difficulties; for example:

a) the table without some numbers, which must be completed (Figure 1 (b));

b) the table without an entire row or column (Figure 1 (c));

c) the table with a missing row or column, with the request to indicate the numbers of certain cells;

d) the table with only one row or one column, with a request to indicate the numbers of certain cells (Figure $1(\mathrm{~d})$ ).

\section{B. Operations and decompositions of numbers}

In relation to operations and decompositions of numbers, it is possible to consider sheets as in Figure 2. Children can be divided into small groups, preferably not too much numerous, for avoiding that the most talented work for all. Sheets as in Figure 2 are delivered and children have to look if there is correspondence among cells. The cells can also be cut out and pasted on a white sheet, in pairs. The operations in the game can be more than one, using not only addition and subtraction, and progressively increasing them. 


\begin{tabular}{|c|c|l|c|c|c|c|c|}
\hline 5 & $3+1$ & & $2+9$ & 11 & & $2-1+8$ & $10+2-1$ \\
\hline 4 & $2+3-1$ & & $2+7$ & 9 & & $13-4+7$ & $16+4-3$ \\
\hline 7 & $3+5-1$ & & $17+13$ & 31 & & $25-9-3$ & $18-4-1$ \\
\hline
\end{tabular}

Figure 2. Operations and decompositions of numbers.

Also the maximum numerical value reached in each cell of the sheet can be gradually increased. Considering a maximum working time, the group finding the most pairs wins. Increasing the age of childrens, the work is adaptable also for multiplication and division, for fractions and for decimal numbers.

\section{The belonging}

Through forms as in Figure 3, it is possible to adequately work on the concept of belonging. In relation to the indicated figure, in particular:

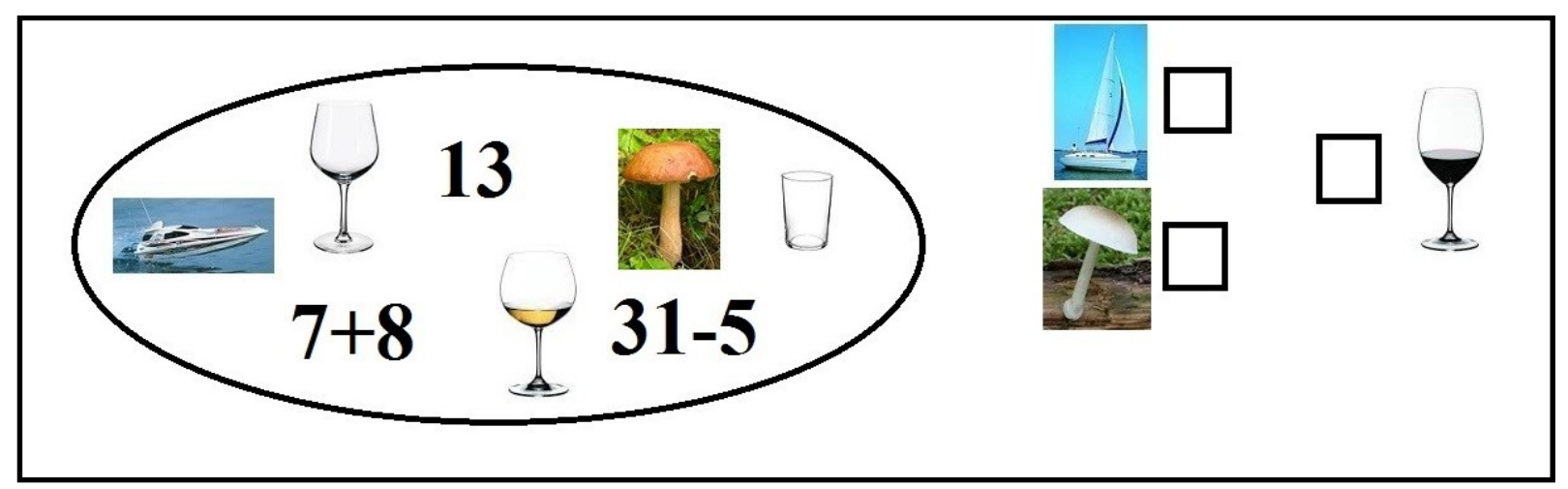

Figure 3. Useful forms for the concept of belonging.

a) it is possible to work on the number of represented objects;

b) in relation to particular colors of objects;

c) in relation to particular characteristics of the objects (shape, size, height, width, depth, etc.);

d) in relation to particular characteristics of the objects: kinds of objects (different glasses, mushrooms, boats, numbers, etc.), liquids inside glasses (water, orange, juice, etc.), with interesting connections with natural sciences [2,10-12].

\section{CONCLUSIONS}

The laboratory of mathematics is a stimulus for teacher, for reflecting, focusing on specific needs and requirements, normally depending by the different class. The showed material can have useful adaptations, in relation to the individual situation of teachers and classes. In particular, in the primary school the laboratory of mathematics has an effective link with the game, by stimulating the imagination of childrens through a fun approach to mathematics. In this way mathematics is perceived as a not heavy and helpful discipline. 
It is useful and informative to start from real contexts, such as:

a) problems that have emerged spontaneously by childrens in difficult situations;

b) problems that may arise in particular contexts.

About the modality of work, the class could be divided:

a) in groups of 4-5 children with inhomogeneous levels of learning;

b) in pairs;

c) with possible time periods of individual work;

d) with the possibility to create new groups in relation to the peculiar characteristics of childrens and work.

It is possible to think of working also on a same problem, performing it in two (or more) different ways. About the integration, students with disabilities can be usefully included in the groups with the mentoring teacher support [1,2,13-15].

\section{Biography}

Paolo Di Sia is currently professor of "Foundations of Mathematics and Didactics" by the Free University of Bolzano-Bozen (Italy). He obtained a Bachelor in Metaphysics, a Laurea in Theoretical Physics and a PhD in Mathematical Modelling applied to Nano-Bio-Technologies. He interested in Classical-Quantum-Relativistic Nanophysics, Theoretical Physics, Planck Scale Physics, Mind-Brain Philosophy, Philosophy of Science, of Physics and of Cosmology, Econophysics, Science Education. He is author of more than 130 works at today (articles on national and international journals, scientific international book chapters, books, internal academic notes, scientific web-pages, in press), reviewer of two mathematics academic books and is preparing a chapter for a scientific international encyclopedia. He is reviewer of some international journals and invited to review and as editor. He obtained 4 international awards, is included in Who's Who in the World 2015 ( $32^{\text {nd }}$ Edition), is member of 5 scientific societies and of 13 International Advisory/Editorial Boards.

http://unibz.academia.edu/PaoloDiSia

http://it.linkedin.com/pub/paolo-di-sia/23/928/8b7

http://paolodisia.weebly.com/

\section{References}

[1] P. Di Sia, Fondamenti di Matematica e Didattica I, Aracne, Roma (2013), ISBN 978-88-548-5889-3, 214 pp.

[2] P. Di Sia, Elementi di Didattica della Matematica I - Laboratorio, Aracne, Roma (2013), ISBN 978-88-548-6040-7, 108 pp.

[3] P. Di Sia, Fondamenti di Matematica e Didattica II, Aracne, Roma (2014), ISBN 978-88-548-7108-3, 344 pp.

[4] P. Perrenoud, Dieci nuove competenze per insegnare. Invito al viaggio, Anicia, Roma (2002).

[5] G. Polya, How to solve it: A new aspect of mathematical method, Princeton University Press, Princeton (1973).

[6] R. (Robert) Burke Johnson, L. B. Christensen, Educational Research: Quantitative, Qualitative, and Mixed Approaches, SAGE Publications, USA, $5^{\text {th }}$ Ed. (2013).

[7] http://hubmiur.pubblica.istruzione.it/alfresco/d/d/workspace/SpacesStore/701c1b68-2184431a-8e1c-e281acec4ab9/indicazioni_nazionali_bozza_pubblica.pdf 
[8] B. Marinas, M. A. Clements, Understanding the problem: A prerequisite to problem solving in mathematics, Journal for Research in Science and Mathematics Education in Southeast Asia 13(1) (1990).

[9] J. Bascones, V. Novak, J. D. Novak, Alternative instructional systems and the development of problem-solving skills in physics, European Journal of Science Education 7 (3) (1985).

[10] H. Singer and D. Donlan, Active Comprehension: Problem-Solving Schema with Question Generation for Comprehension of Complex Short Stories, Reading Research Quarterly 17(2) (1982).

[11] D. Ausubel, J. Novak, H. Hanesian, Educational Psychology: A Cognitive View, Holt, Rinehart \& Winston, New York, $2^{\text {nd }}$ Ed. (1978).

[12] E. von Glasersfeld, The radical constructivist view of science, Foundation of Science, 6 (2001).

[13] M. Walshaw (Ed.), Unpacking Pedagogy: New Perspectives for Mathematics Classrooms, International Perspectives on Mathematics Education: Cogniti, Information Age Publishing, USA (2010).

[14] J. A. Van de Walle, K. S. Karp, J. M. Bay-Williams, Elementary and Middle School Mathematics: Teaching Developmentally, Teaching Student-Centered Mathematics Series, Pearson, USA, $8^{\text {th }}$ Ed. (2012).

[15] T. L. Contant, J. E. Bass, A. A. Carin, Teaching Science Through Inquiry and Investigation, Pearson, USA (2014). 